\title{
Development and Regulation of Dendrites in the Rat Superior Cervical Ganglion
}

\author{
James T. Voyvodic \\ Department of Anatomy and Neurobiology, Washington University School of Medicine, St. Louis, Missouri 63110
}

Intracellular injection of HRP was used to study the postnatal development of dendrites in the rat superior cervical ganglion (SCG). This study had 2 goals: to describe the growth of dendrites during normal development and to determine the influence of preganglionic innervation on dendritic growth. At birth, ganglion cell morphology is relatively simple; cells have few dendritic branches and an average total dendritic length under $300 \mu \mathrm{m}$. In the first postnatal month there is a 4-fold increase in dendritic length and a marked increase in the complexity of branching. Dendrites continue to grow into adulthood; at each age studied (up to 16 months old), the dendritic geometries of SCG cells became progressively more extensive and complex.

The influence of innervation on the development of dendrites was assessed by cutting the cervical sympathetic trunk (CST) within a day of birth; reinnervation was prevented by ligating and displacing the proximal end of the CST. During the first postnatal month, the cells in denervated ganglia showed an increase in dendritic length indistinguishable from that seen in unoperated control ganglia. The rate of growth after 1 month was somewhat slower in experimental animals than in controls; nevertheless, the dendrites of cells in denervated ganglia showed progressively larger arbors at each time point measured.

These results indicate that in the SCG (1) the majority of dendritic growth occurs postnatally, (2) dendrites continue to grow in adult rats, and (3) dendritic growth is largely independent of the presence of preganglionic innervation. The significance of these findings for the regulation of innervation in this part of the nervous system is discussed.

Dendritic variation is one of the most striking features of nerve cells. Within the vertebrate nervous system, neuronal geometries range from simple cells without dendrites to elaborate neurons having thousands of dendritic branches. Although the role of dendrites is not completely understood, differences in dendritic complexity are related to at least 2 important aspects of

\footnotetext{
Received June 4, 1986; Revised Aug. 9, 1986; accepted Aug. 19, 1986.

This work was supported by a National Science Foundation Graduate Fellowship to J.V. and by grants from the National Institutes of Health (NS 11699 and 18629) and the Muscular Dystrophy Association to Dale Purves. Computer morphometry was made possible by an NIH Program Project grant (NS 17763). I thank D. Purves for support and advice throughout this study and C. Forehand and W. Snider for useful comments on the manuscript. I also thank P. Newton and $D$. Dill for their excellent technical assistance.

Correspondence should be addressed to James T. Voyvodic, Department of Anatomy and Neurobiology, Washington University School of Medicine, $660 \mathrm{~S}$. Euclid Avenue, St. Louis, MO 63110.

Copyright (C) 1987 Society for Neuroscience $0270-6474 / 87 / 030904-09 \$ 02.00 / 0$
}

neuronal function: the propagation and integration of electrical potentials (see Rall, 1977; Miller and Jacobs, 1984, for reviews), and the number of different inputs that converge onto individual postsynaptic cells (Purves and Hume, 1981; Purves, 1983; Purves and Lichtman, 1985). Despite the enormous diversity of dendritic form and the functional importance of dendrites, relatively little is known about how dendrites develop or the factors that are involved in regulating dendritic morphology.

Since dendrites are usually sites of synapse formation, the developmental relationship between dendritic growth and the presence of presynaptic innervation is of particular interest. Do presynaptic axons modulate the growth of dendrites or, conversely, do growing dendrites regulate synapse formation? Support for the idea that innervation regulates dendritic geometry comes from observations of normal development (e.g., Morest, 1969; Rakic, 1972; Berry et al., 1978), as well as from a number of experimental systems where removal of presynaptic inputs can prevent normal dendritic outgrowth, and may even cause retraction of existing arbors (Larsell, 1931; Levi-Montalcini, 1949; Benes et al., 1977; Deitch and Kubel, 1984). In the autonomic nervous system, however, removal of inputs in adult animals has been reported to have relatively little effect on the average morphology of sympathetic ganglion cells (McLachlan, 1974). Indeed, there is some evidence to suggest that the dendritic geometry of autonomic ganglion cells is involved in modulating preganglionic innervation (Hume and Purves, 1981).

In order to investigate the influence of innervation on dendrites in both neonatal and adult life, I have studied the elaboration of dendrites in the rat sympathetic superior cervical ganglion (SCG). This simple system offers a number of advantages. First, the neurons of the SCG comprise a morphologically relatively homogeneous population, all cells having significant dendritic arbors. These neurons receive synaptic connections from preganglionic axons that enter the ganglion by way of a single nerve, the cervical sympathetic trunk; thus, the inputs to the ganglion can be easily isolated from its outputs, which almost all leave via separate postganglionic nerves. Finally, the ganglion and its pre- and postganglionic nerves are conveniently located in the neck, readily accessible for observation and experimental manipulation. In the work reported here I have examined (1) the normal elaboration of ganglion cell dendrites and (2) the development of these dendrites following removal of the preganglionic innervation at birth. My results indicate that most dendritic growth occurs postnatally in this system, and continues even in fully adult animals. Postnatal dendritic growth appears to be largely independent of the presence of preganglionic inputs; this implies an alternative mechanism of dendritic regulation in this system. 

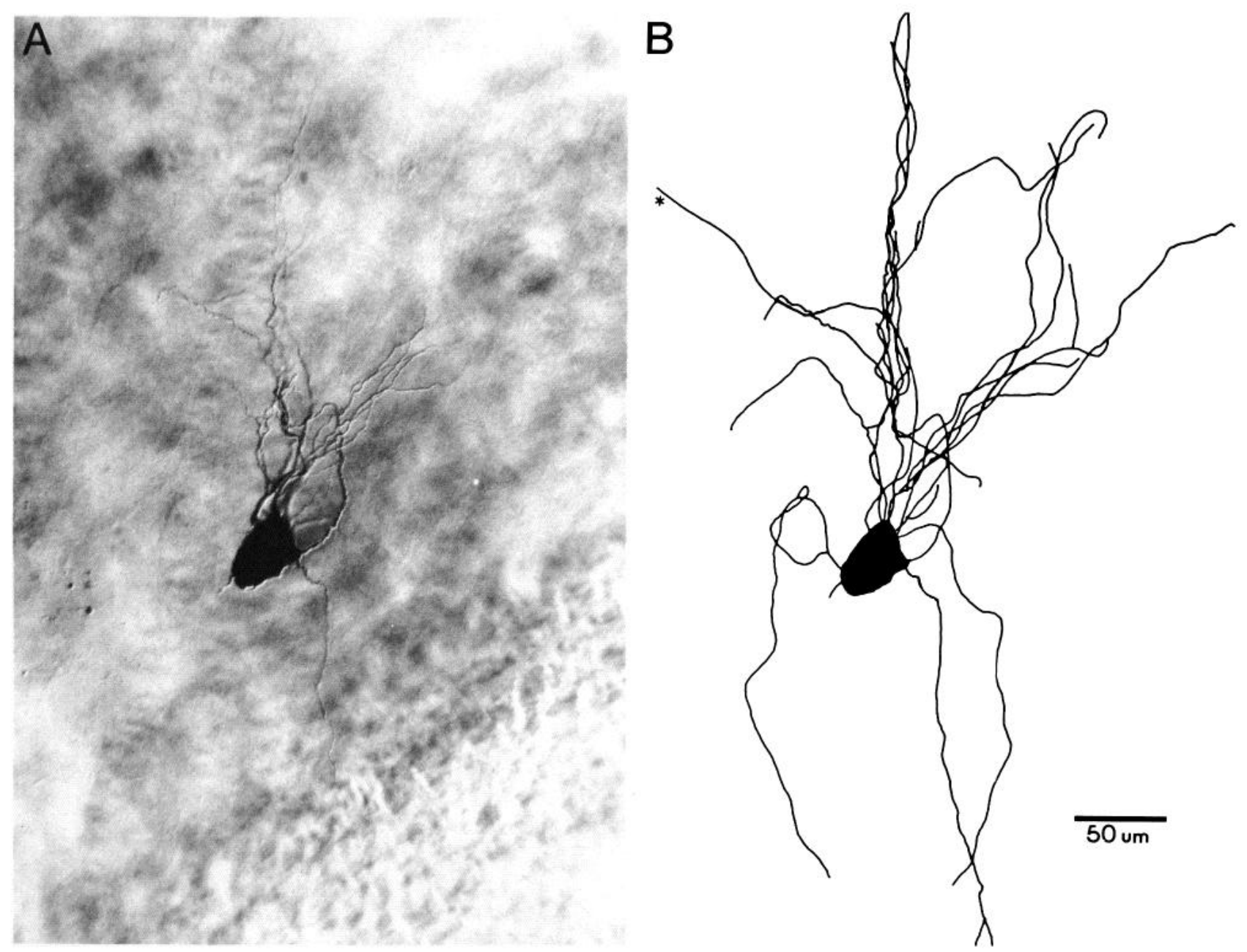

Figure 1. Method of camera lucida tracing of HRP-injected neurons. A, Nomarski photomicrograph of a labeled SCG cell. B, Camera lucida reconstruction of the same cell showing the full extent of the dendritic arbor. The reconstruction is made by focusing through the cell and tracing the cell body and all labeled processes using a camera lucida drawing tube. All branches are drawn with uniform width regardless of variations in dendritic diameter; this convention applies to all subsequent camera lucida figures. The axon is indicated by an asterisk.

\section{Materials and Methods}

Litters of Sprague-Dawley albino rats were bred in the local animal facility. Most of the animals in each litter (male and female) served as normal, unoperated controls; littermates were randomly selected to study the effect of preganglionic denervation on dendritic development. The dendritic geometry of both normal and chronically denervated SCG neurons was measured at several time points: neonatal ( $0-2 \mathrm{~d}$ old), juvenile (28-31 d old), young adult (85-95 d old), and mature adult (210-220 d old). At each of these ages approximately 50 ganglion cells were labeled intracellularly with HRP. An additional population of 43 cells was collected from older control animals (450-500 d old) to determine whether dendrites continued to grow in old adult animals.

Visualizing dendritic geometry with HRP. Animals were anesthetized with pentobarbitol $(50 \mathrm{mg} / \mathrm{kg})$ and perfused through the heart with oxygenated mammalian Ringer's solution to remove the blood. The right SCG was dissected free and placed in a recording chamber at room temperature continuously superfused with fresh oxygenated saline solution (Johnson and Purves, 1981). Individual neurons were impaled with triangular glass microelectrodes (Glass $\mathrm{Co}$. of America) filled with a $5 \%$ solution of HRP (Sigma type 6) in $0.2 \mathrm{M} \mathrm{KAc}$ in Tris buffer $(0.2$ $\mathrm{M}, \mathrm{pH}$ 7.6) (the electrodes were backfilled with $1 \mathrm{M} \mathrm{KCl}$ and had resistances between 120 and $200 \mathrm{M} \Omega$ ). Neurons were filled with HRP by iontophoresis if they met the criterion of an action potential of at least $60 \mathrm{mV}$ in response to intracellular current injection. Neonatal cells do not usually show such large spikes after impalement; in newborn animals, therefore, this criterion was relaxed so that any impalement with an excitatory postsynaptic response to preganglionic stimulation was accepted.

In each ganglion, 5-15 cells were injected with HRP [ $5 \mathrm{~Hz}, 50 \mathrm{msec}$ pulse, 3-5 nA depolarizing current for $3 \mathrm{~min}$ (neonates) or $6 \mathrm{~min}$ (older animals)]. The population of neurons injected included both superficial cells, as well as cells situated deep within the ganglion. After $30 \mathrm{~min}$ to allow the HRP to diffuse throughout the last cell injected, the ganglion was fixed overnight ( $1.25 \%$ glutaraldehyde, $0.5 \%$ paraformaldehyde) before processing the HRP reaction product by the method of Hanker et al. (1977). The ganglion was then dehydrated through a series of graded ethanol solutions, cleared overnight in methyl benzoate, and mounted whole on a microscope slide with DPX.

Quantitative analysis of dendritic geometry. Approximately $75 \%$ of the ganglion cells injected with HRP were sufficiently well stained to be used for measuring dendritic geometry. Cells were considered unacceptable if the cell body or dendrites were weakly labeled, or if the axon could not be followed at least several hundred microns away from the cell body; the axons of most cells could be traced into one of the postganglionic nerves. Cells were also rejected if their dendrites appeared discontinuous or if their dendritic arbors overlapped extensively with neighboring labeled cells.

All HRP-filled cells that met these criteria were traced with a light microscope equipped with a drawing tube (Fig. 1). Quantitative measurements of dendritic lengths and cell body size were made from these camera lucida tracings using a digitizing tablet (Summagraphics) with my own software (Voyvodic, 1986) running on a PDP 11/44 computer. Measuring a 2-dimensional projection necessarily results in an under- 
estimate of the total length of a 3-dimensional arbor. However, since the same approach was used for all the neurons studied, this method provides a fairly accurate measure of relative dendritic length. The number of primary dendrites was determined by counting dendritic processes that extended radially from the cell soma at least 1 cell body diameter in length

Development of dendrites after preganglionic denervation. The development of dendrites in the absence of preganglionic innervation was studied in littermates of the animals used to study normal development. Neonatal rat pups ( $0-1 \mathrm{~d}$ old) were anesthetized by cooling; the right preganglionic cervical sympathetic trunk (CST) was exposed and ligated approximately halfway between the SCG and the first rib (Fig. 2). The sympathetic trunk was then transected rostral to the ligation; the ligated nerve stump was displaced ventrally and tucked under the skin of the neck to prevent reinnervation. After closing the wound these experimental animals were returned to the litter. Dendritic geometry of cells in chronically denervated ganglia was evaluated in animals at 4, 12, and 30 weeks of age.

All denervated animals exhibited chronic, pronounced ptosis of the right eye. Complete denervation was verified in each of the operated animals by electrophysiological observations on the day of sacrifice. Ganglia were tested by recording the postganglionic nerve response to electrical stimulation of the stump of the CST. Two ganglia, both early in the series, showed a small compound action potential response and were not considered further. As an additional test, the response of individual ganglion cells to stimulation of the cervical trunk was recorded intracellularly. Most cells ( $>97 \% ; N=250)$ showed no response to CST stimulation. A few cells $(<3 \%)$ located in the caudal end of the ganglion showed some response to CST stimulation and were excluded from the study; these responses may have arisen from intraganglionic connections of those cells whose axons travel in the preganglionic nerve stump (see Bowers and Zigmond, 1979), rather than as a result of reinnervation (see Results).

Synapse counts. Two ganglia from both denervated and control animals at 4 weeks of age were processed for electron microscopy. These animals were anesthetized and perfused through the heart with saline solution $(0.9 \% \mathrm{NaCl})$, followed by perfusion with $300 \mathrm{ml}$ of fixative $(2 \%$ paraformaldehyde, $2 \%$ glutaraldehyde, $4 \%$ sucrose in $0.1 \mathrm{M}$ phosphate buffer). The ganglia were postfixed in osmium $\left(2 \% \mathrm{OsO}_{4}\right.$ in $0.1 \mathrm{M}$ phosphate buffer), dehydrated through a series of graded acetone solutions, and embedded in Araldite. Thin sections were cut longitudinally and placed on 400 mesh grids, stained with uranyl acetate and lead citrate, and viewed with a Zeiss EM. The tissue was scanned for synaptic profiles, defined by clustered presynaptic vesicles opposed by a postsynaptic membrane thickening. Synapses were counted in 6 grid squares (totaling $48,600 \mu \mathrm{m}^{2}$ ) from each ganglion.

\section{Results}

\section{Normal dendritic growth}

The time course of normal dendritic development in the SCG was studied in litters of rats over a 16 month period. Camera lucida tracings of representative ganglion cells from normal animals at 4 different ages are shown in Figure 3 . At birth, rat SCG cells already exhibit several short dendrites; indeed, some dendritic growth is evident as early as embryonic day 14 (Rubin,

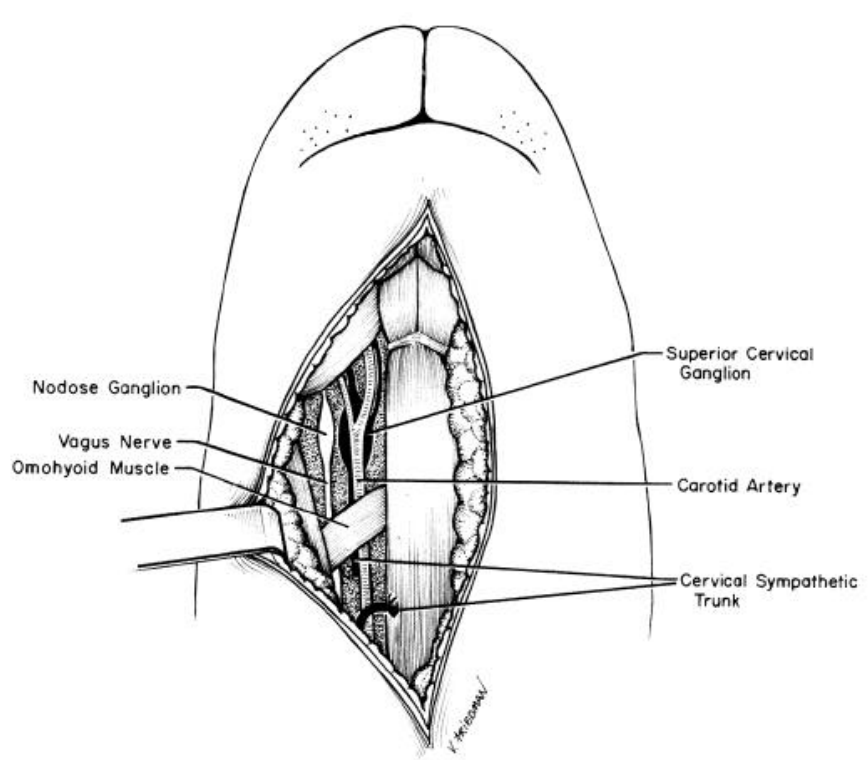

Figure 2. Diagram showing the method used for preganglionic denervation of the SCG in a newborn rat. The pup is anesthetized and the right cervical sympathetic trunk exposed. The preganglionic nerve is ligated and cut as shown. Reinnervation is prevented by displacing the ligated central end of the nerve and sewing it into the connective tissue overlying the trachea.

1985). As the animal grows postnatally, there is a dramatic increase in both dendritic length and complexity. After a few weeks, most cells have formed fairly elaborate branching patterns with dendrites extending many cell body diameters in length. Over the first postnatal month total dendritic length increased more than $400 \%$ (Fig. 4), and between 4 weeks and 30 weeks the total length of the dendritic arbor increased by an additional $87 \%$. Even in fully adult animals there was a further $15 \%$ increase in total dendritic length between 30 and 70 weeks of age.

Other parameters related to ganglion cell growth are summarized in Table 1. Three trends were noted. First, as the animal grows, the size of ganglion cell bodies increases steadily; thus, between birth and 30 weeks cell body diameter almost doubled. Second, over the first postnatal month the number of primary dendrites increased by $22 \%$. Beyond 1 month this number remained constant, averaging $6.6 \pm 0.2$ primary dendrites. Third, the overall size of the dendritic tree, determined by measuring the distance from the center of the cell body to the furthest point on the arbor, increased as the animals grew (Table 1). However,

Table 1. Summary of the growth of rat SCG cells at various ages

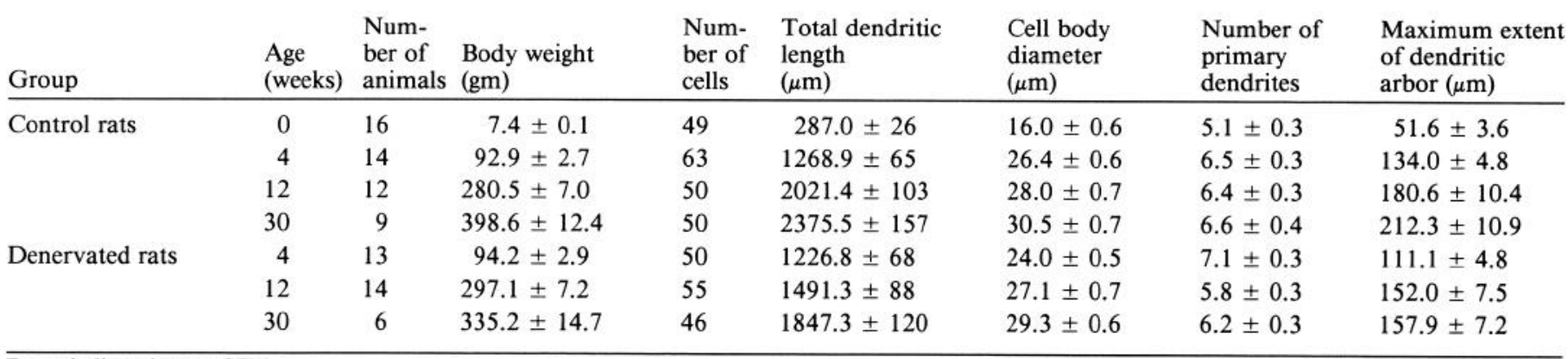




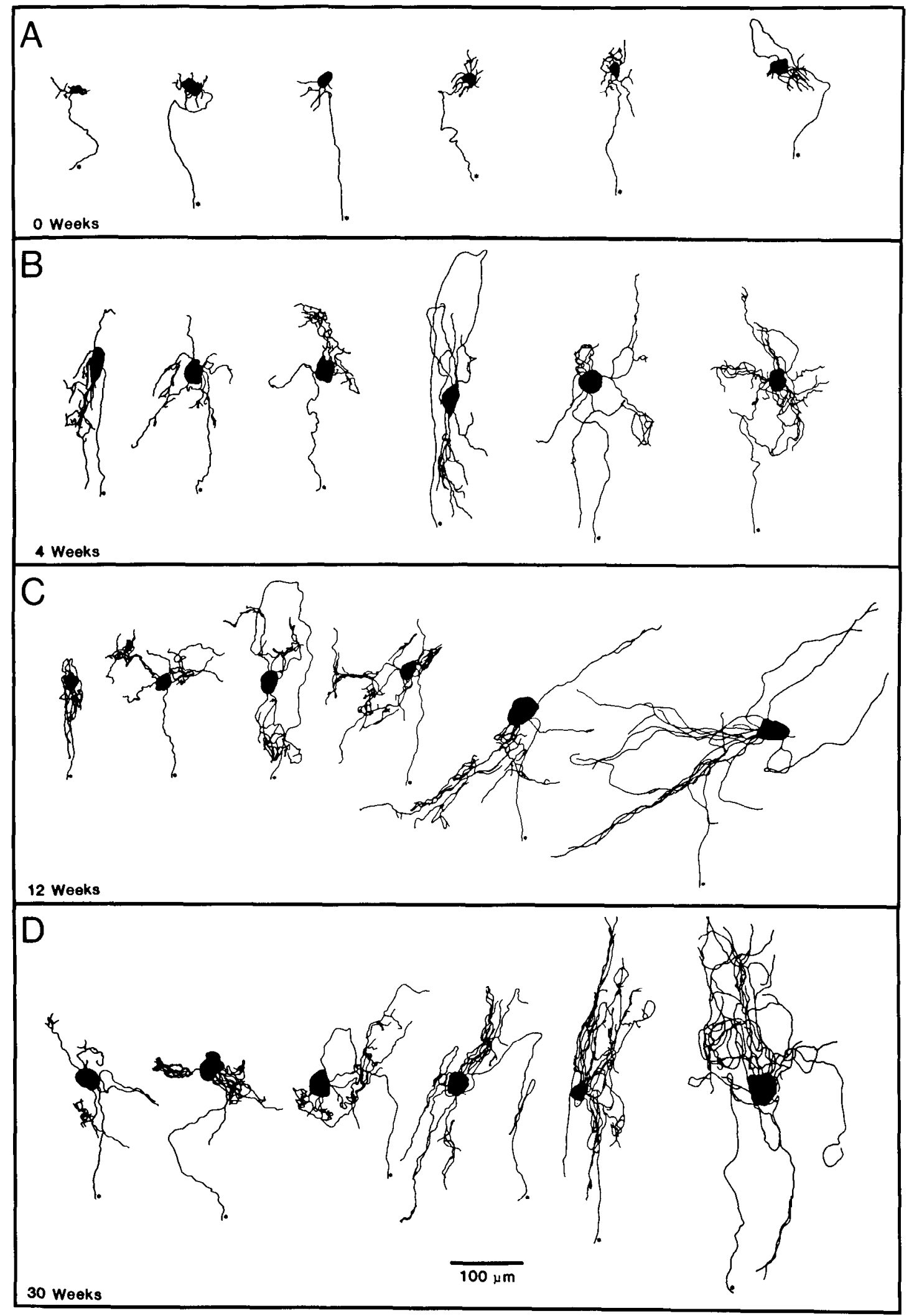

Figure 3. Camera lucida drawings of HRP-labeled SCG cells from normal, unoperated rats at 4 different ages. At each age the 1st, 10th, 20th, $30 \mathrm{th}, 40 \mathrm{th}$, and last cell studied were arbitrarily selected; the 6 cells were then arranged from left to right in order of increasing total dendritic length to indicate the range of geometries. The diameters of all processes are drawn of uniform width (see Fig. 1). For each cell the axon is labeled with an asterisk. Cells are from animals $0-2 \mathrm{~d}$ old $(A), 28-31 \mathrm{~d}$ old $(B), 83-95 \mathrm{~d}$ old $(C)$, and $210-225 \mathrm{~d}$ old $(D)$. The scale bar applies to all 5 panels. 
Figure 4. Dendritic growth in normal ganglia as a function of age. Total dendritic length was measured hy summing the lengths of all the branches within a particular dendritic arbor. Each point represents the mean of $43-63$ cells (see Table 1). Error bars are SEM.

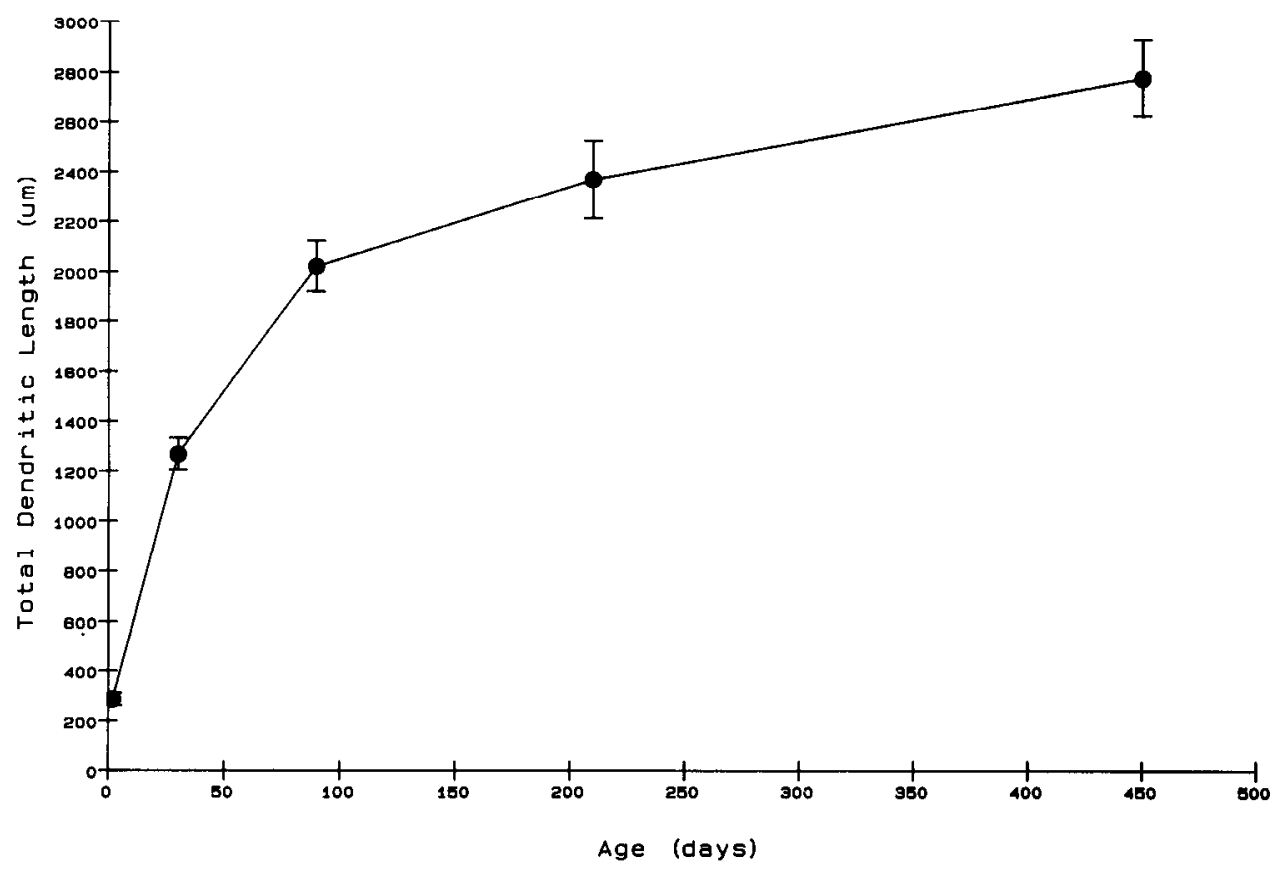

the ratio between the maximum extent of the arbor and the arbor's total dendritic length was the same (9-11\%) at 4,12 , and 30 weeks of age. Although there is considerable heterogeneity in the geometries of individual cells, the constancy of this ratio suggests that, on average, the overall shape of the arbor simply expands linearly as dendritic length increases.

\section{Overall animal growth}

The body weight of the rats increased throughout the period studied. In general, the growth of dendrites is well correlated with the overall growth of the animal (Figure 5). Although the difference in body weight between male and female adult rats is substantial, there is no significant difference in dendritic growth between male and female rats when ganglion cell dendritic length is considered as a function of body weight, rather than animal age.

\section{Dendritic growth in denervated ganglia}

The growth of dendrites in denervated superior cervical ganglia is qualitatively similar to that in normal ganglia. Figure 6 shows camera lucida tracings of representative cells from denervated ganglia in animals at 4,12 , and 30 weeks of age. During the first month after birth, ganglion cells lacking preganglionic innervation showed a 4- to 5-fold increase in total dendritic length. This increase was identical to the increase observed for normally innervated cells (Fig. 7). In older animals, however, the rate of dendritic growth of the denervated neurons was slower than that observed in normal cells at comparable ages. For instance, be-
Figure 5. Dendritic growth in the SCG as a function of body weight. Total dendritic length is plotted against body weight for normal rats. Malc and female rats are included together (see text). Animals were separated into bins based on weight (0-50 gm, 50-200 gm, 200-400 $\mathrm{gm}$, and 400-600 gm). Each point represents the mean of the dendritic lengths of all cells labeled in animals within the weight range. Error bars are SEM.

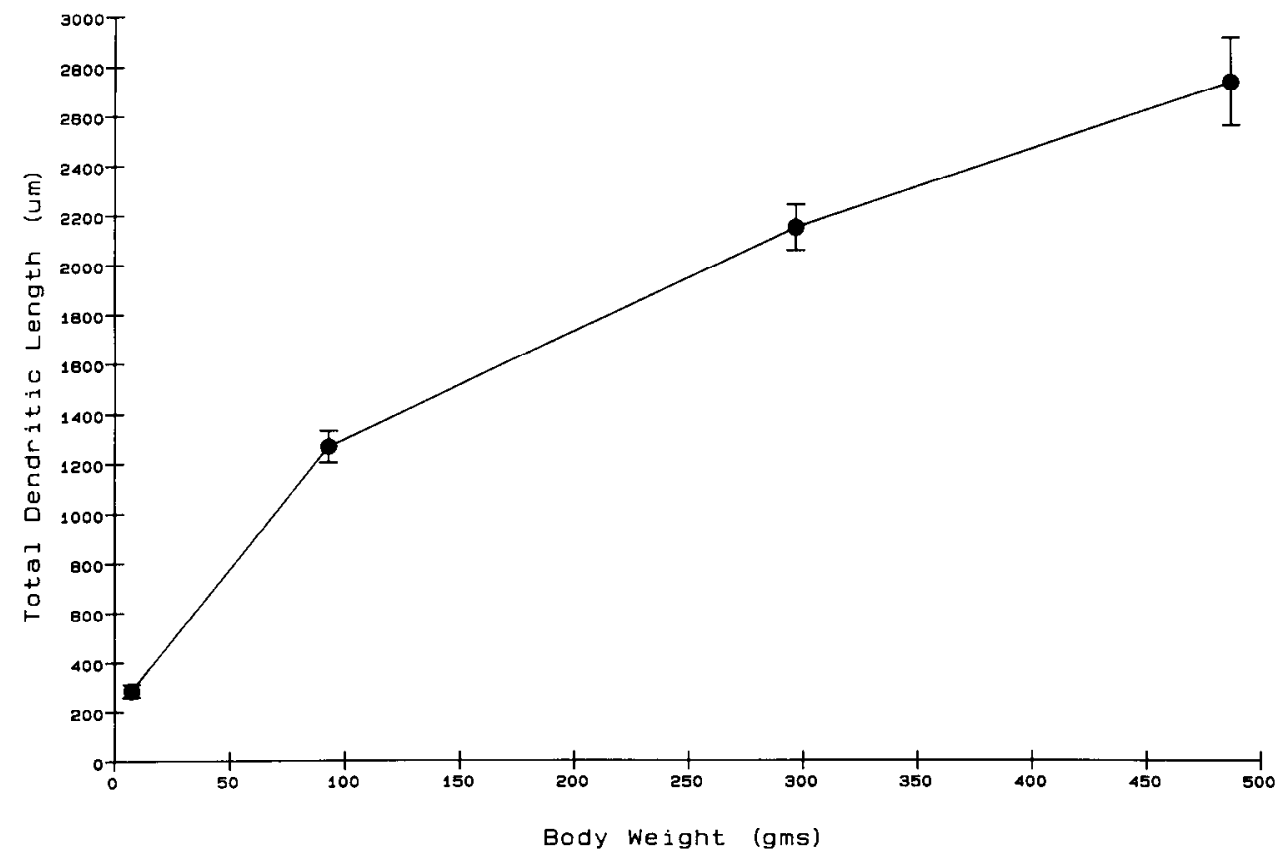




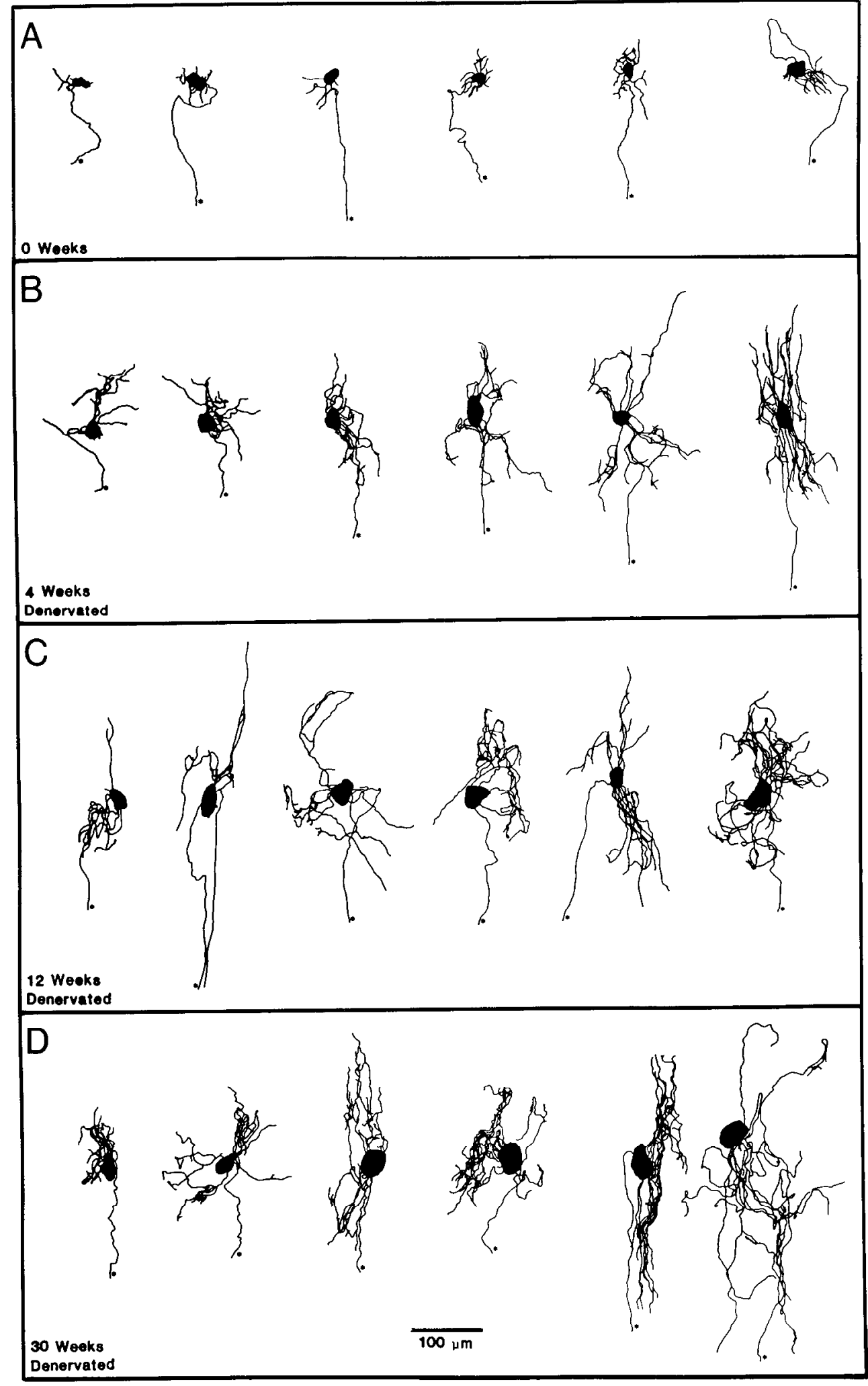

Figure 6. Camera lucida tracings of HRP-labeled SCG cells from ganglia denervated since birth (see Materials and Mcthods). For each panel, 6 cells were selected, drawn, and arranged as described for Figure 3. $A$, Normal cells from animals $0-2 \mathrm{~d}$ old; these are the same cells as Figure $3(A)$ and indicate dendritic complexity at the time of denervation. $B$, Cells from denervated ganglia in animals $28-31 \mathrm{~d}$ old. $C$, Cells from denervated ganglia in animals $85-$ 95 d old. $D$, Cells from denervated ganglia in animals $210-225 \mathrm{~d}$ old. The scale bar applies to all 4 panels. tween 4 and 30 weeks of age, total dendritic length increased by $47 \%$, compared with an $87 \%$ increase in control animals. Nevertheless, the dendrites of cells in denervated ganglia continued to grow substantially, showing a continuous and significant increase in the average dendritic length at each time point studied (Fig. 7). Even 3-6 months after denervation, dendritic growth continued in the absence of preganglionic innervation.

There was no obvious difference in the overall size or branching of dendritic trees between control and denervated ganglion cells. Furthermore, at all ages studied, denervated ganglion cells possessed the same number of primary dendrites as control cells (Table 1). Although the total dendritic length at 12 or 30 weeks 
Figure 7. Dendritic growth in normal SCG and in ganglia lacking preganglionic innervation since birth. Total dendritic length was measured for each cell; each point represents the mean of approximately 50 cells. The curve for denervated growth is extrapolated back to the day of birth for comparison purposes. Error bars are SEM.

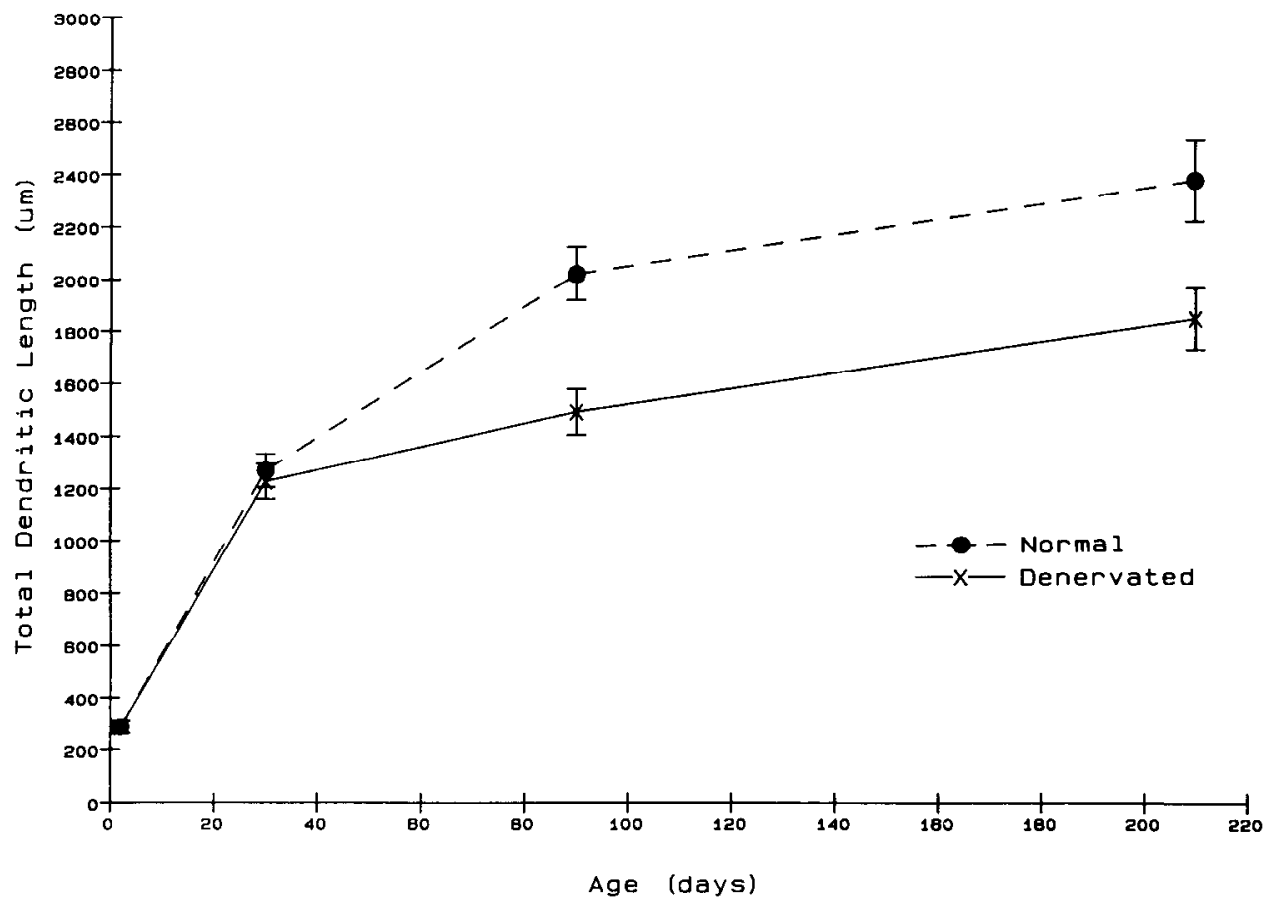

(see also Smolen and Beaston-Wimmer, 1984; Voyvodic and Purves, 1984). Although several months of denervation resulted in a somewhat slower rate of growth than normal, chronically denervated ganglion cells continued to expand their dendritic arbors throughout the period studied (7 months). These results raise a number of issues regarding the regulation of dendritic growth and the relationship between dendritic development and synapse formation.

\section{Normal development of dendrites}

My results show that the elaboration of dendrites in the SCG is clearly not restricted to what is generally considered the devclopmental period since there is no indication that dendritic geometry ever reaches a fully mature, stable state; dendrites continue to grow even in adult animals (see also Purves et al., 1986). As the dendrites grow, the entire spectrum of geometries shifts toward greater complexity; thus, the simplest cells at each time point have larger dendritic arbors than the simplest cells at younger ages (see Fig. 2). Continued dendritic growth is therefore not confined to a subpopulation of exuberant cells, but appears to be a general feature of neurons in the ganglion. Recent studies of the SCG indicate that the growth of dendrites is not a process of simple elongation; rather, it appears to involve continual extension and retraction of individual branches (Purves et al., 1986). The overall growth reported here presumably reflects the predominance of extension over retraction, resulting in a net increase in total dendritic length.

The fact that dendritic growth continues in adult animals implies that the mechanisms regulating the length of dendrites continue to function throughout life. Indeed, it seems likely that the processes that govern dendritic length in older animals are the same as those that act during early development. Ongoing regulation of dendritic growth in maturity might be an efficient means for these neurons to continuously adjust to other relevant changes in the animal, for instance, to changes in size of sympathetic target organs (see below). Interestingly, the number of primary dendrites, i.e., those arising directly from the cell body, much affected by removing preganglionic innervation at birth
I have described the normal growth of dendrites in the rat SCG and investigated the influence of preganglionic innervation in the regulation of dendritic development. My results support 3 conclusions. First, most dendritic growth in this system occurs postnatally (see also Rubin, 1985; Snider, 1986). Second, dendrites continue to grow well into adult life (at least through 16
months of age). Third, the elaboration of dendrites is not very 
appears to be regulated somewhat differently than dendritic length, since the initiation of new primary dendrites is apparently restricted to prenatal or neonatal development. Unlike dendritic length, which changes continuously, the average number of primary dendrites does not change at all after 4 weeks of age (see Table 1).

\section{The influence of preganglionic innervation}

Dendritic development is not much affected by preganglionic denervation. During the first postnatal month, when dendritic growth is most rapid, dendrites of cells in denervated ganglia are indistinguishable from normal. Furthermore, ongoing dendritic growth in adult animals, although somewhat slowed compared to normal, nevertheless persists for at least 30 weeks in the absence of preganglionic innervation. The fact that dendritic growth is so little affected by denervation is somewhat surprising since removal of preganglionic innervation significantly affects ganglion cell development in other ways. For example, neonatal denervation prevents the biochemical maturation of neurons in the ganglion in that denervated ganglia do not exhibit the normal postnatal increase of tyrosine hydroxylase (Black et al., 1971; Smolen et al., 1985).

Another consequence of SCG denervation is abnormal development of ganglion cell projections in postganglionic target tissues. In the targets of chronically denervated ganglia, the terminal arborizations of sympathetic axons are less dense than in controls (Black and Mytilineou, 1976; Lawrence et al., 1979). Furthermore, cutting the preganglionic trunk at birth retards the overall growth of some target organs (Hillarp, 1949). The extent of these denervation-induced changes in target tissues suggests that the modest depression in dendritic growth apparent a month or more after denervation may be a secondary effect of target atrophy, rather than a primary consequence of prolonged denervation (see below).

\section{Dendritic growth and target size}

Although ganglion cell dendrites are not dramatically affected by their presynaptic innervation, neither are they determined solely by intrinsic properties. My results provide circumstantial evidence that the primary influence regulating ganglion cell dendrites may be a retrograde signal from postganglionic target tissues. First, dendritic growth is well correlated with overall somatic growth during normal development (see Fig. 5). Second, the reduction in dendritic length (see Fig. 7) that is seen in preganglionically denervated animals is associated with a decrease in the size of at least some target organs. This was confirmed in the present study by measuring the change in weight of the submandibular gland following denervation of the SCG: In 4 animals in which the right ganglion was denervated at birth, the ratio between the weights of the right and left glands at 12 weeks of age was $26 \pm 4 \%$ lower than in controls $(n=5)$ (see also Hillarp, 1949). Although the role of the target in regulating dendritic growth has yet to be tested directly, my data suggest that such a relationship is likely. Finally, other reports indicate that disrupting a neuron's connection with its target by postganglionic nerve crush can lead to a reduction in dendritic length (Yawo, 1986; see also Sumner and Watson, 1971; Standler and Bernstein, 1982).

\section{Dendritic growth and synapse formation}

Dendritic geometry in autonomic ganglia is related to 2 important aspects of preganglionic innervation. First, there is a strong correlation in adult animals between the number of primary dendrites and the number of different inputs that converge onto individual ganglion cells (Purves and Hume, 1981; Purves and Lichtman, 1985; and W. D. Snider, unpublished observations). Second, although the number of different axons contacting each ganglion cell is relatively small, the number of synaptic boutons made by the innervating axons is relatively large and varies with the size of the postsynaptic dendritic arbor (Forehand, 1985). Since the number of primary dendrites of these neurons does not change beyond 1 month of age (see Table 1), my results suggest that the degree of preganglionic convergence onto ganglion cells is probably stable in adult animals. However, the fact that dendritic length continues to increase in adult animals implies that there are ongoing changes occurring in the number and location of individual synaptic contacts (see also Purves et al., 1986). Since preganglionic denervation has relatively little effect on dendritic growth, the correlation between dendritic length and number of synapses cannot be the result of preganglionic axons regulating dendritic growth. On the contrary, the results of the present study imply that growing dendrites stimulate the formation of new synapses. In general, regulation of the dendritic arbor by retrograde signals might provide a mechanism by which the peripheral target could continuously modulate the strength of its associated synaptic connections within the ganglion. This idea is consistent with other studies that demonstrate the importance of the target in maintaining ganglionic synapses (Purves, 1975, 1976; Nja and Purves, 1978).

\section{Mechanisms regulating dendritic growth in different parts of the nervous system}

The finding that sympathetic ganglion cell dendrites continue to grow after preganglionic denervation is quite different from observations in some other regions of the nervous systemprimarily sensory systems - where dendritic growth is severely reduced by denervation (see Berry et al., 1978, for review). For example, in chick brain stem auditory nuclei, cells deprived of their synaptic inputs fail to develop normal dendrites and may even retract existing dendritic arbors (Levi-Montalcini, 1949; Benes et al., 1977; Deitch and Rubel, 1984). In some cases, altering the pattern of presynaptic activity is sufficient to produce regressive changes in dendritic morphology (Wiesel and Hubel, 1963; Spencer and Coleman, 1974; Harris and Woolsey, 1981; Gray et al., 1982). On the other hand, the length of dendrites of spinal motor neurons-like the visceral motor neurons studied here-are relatively insensitive to disruption of descending central connections (Standler and Bernstein, 1984) but become shorter in response to axotomy of their peripheral connections (Sumner and Watson, 1971; Standler and Bernstein, 1982). A possible explanation for these various observations is that there may be a fundamental difference in the regulation of dendrites in sensory and motor portions of the nervous system. Sensory systems are functionally centripetal in nature, whereas motor systems are functionally centrifugal. Accordingly, dendrites of neurons in sensory systems may, in general, be regulated primarily by the innervation they receive, whereas dendrites of motor neurons may be regulated primarily by a retrograde influence arising from the targets the neurons innervate.

Admittedly, this simple view cannot predict how dendritic geometry will be affected in regions of the CNS where many different input and output pathways are present. However, the traditional view that innervation regulates the elaboration of 
dendrites is clearly not valid in all cases. Other influences, including retrograde signals from target tissues, may be at least as important as innervation in determining a neuron's dendritic arbor. Sorting out the signals that regulate the growth of dendrites in simple parts of the nervous system, such as autonomic ganglia, should help achieve some general understanding of the regulation of neuronal geometry and associated changes in synaptic connectivity.

\section{References}

Benes, F. M., T. N. Parks, and E. W. Rubel (1977) Rapid dendritic atrophy following deafferentation: An EM morphometric analysis. Brain Res. 122: 1-13.

Berry, M., P. Bradley, and S. Borges (1978) Environmental and genetic determinants of connectivity in the central nervous system-An approach through dendritic field analysis. Prog. Brain Res. 48: 133148.

Black, I. B., and C. Mytilineou (1976) Trans-synaptic regulation of the development of end organ innervation by sympathetic neurons. Brain Res. 101: 503-521.

Black, I. B., I. A. Hendry, and L. L. Iversen (1971) Trans-synaptic regulation of growth and development of adrenergic neurons in a mouse sympathetic ganglion. Brain Res. 34: 229-240.

Bowers, C. W., and R. E. Zigmond (1979) Localization of neurons in the rat superior cervical ganglion that project into different postganglionic trunks. J. Comp. Neurol. 185: 381-392.

Deitch, J. A., and E. W. Rubel (1984) Afferent influences on brain stem auditory nuclei of the chicken: Time course and specificity of dendritic atrophy following deafferentation. J. Comp. Neurol. 229 66-79.

Forehand, C. J. (1985) Density of somatic innervation on mammalian autonomic ganglion cells is inversely related to dendritic complexity and preganglionic convergence. J. Neurosci. 5: 3403-3408.

Gray, L., Z. Smith, and E. W. Rubel (1982) Developmental and experiential changes in dendritic symmetry in $\mathrm{n}$. laminaris of the chick. Brain Rcs. 244: 360-364.

Hamlyn, L. H. (1954) The effect of preganglionic section on the neurons of the superior cervical ganglion in rabbits. J. Anat. 88: 184.

Hanker, J. S., P. E. Yates, C. B. Metz, and A. Ristioni (1977) A new specific sensitive and non-carcinogenic reagent for the demonstration of horseradish peroxidase. Histochem. J. 9: 789.

Harris, R. M., and T. A. Woolsey (1981) Dendritic plasticity in mouse barrel cortex following postnatal vibrissa follicle damage. J. Comp. Neurol. 196: 357-376.

Hillarp, N.-A. (1949) Some critical remarks on the problem of the double innervation of salivary gland cells. Acta Anat. 8: 190-200.

Hume, R. I., and D. Purves (1981) Geometry of neonatal neurones and the regulation of synapse elimination. Nature 293: 469-471.

Johnson, D. A., and D. Purves (1981) Postnatal reduction in neural unit size in the rabbit ciliary ganglion. J. Physiol. (Lond.) 318: 143159.

Larsell, O. (1931) The effect of experimental excision of one eye on the development of the optic lobe and opticus layer in larvae of the tree frog (Hyla regilla). II. The effect on cell size and differentiation of cell processes. J. Exp. Zool. 58: 1-20.

Lawrence, J. M., I. B. Black, C. Mytilineou, P. M. Field, and G. Raisman (1979) Decentralization of the superior cervical ganglion in neonates impairs the development of the innervation of the iris. A quantitative ultrastructural study. Brain Res. 168: 13-19.

Levi-Montalcini, R. (1949) The development of the acoustico-vestibular centers in the chick embryo in the absence of afferent root fiber and of descending fiber tracts. J. Comp. Neurol. 91: 209-241.

McLachlan, E. M. (1974) The formation of synapses in mammalian sympathetic ganglia reinnervated with preganglionic or somatic nerves. J. Physiol. (Lond.) 237: 217-242.

Miller, J. P., and G. A. Jacobs (1984) Relationships between neuronal structure and function. J. Exp. Biol. 112: 129-145.

Morest, D. K. (1969) The growth of dendrites in the mammalian brain. Z. Anat. Entwickl.-Gesch. 128: 290-317.
Nja, A., and D. Purves (1978) The effects of nerve growth factor and its antiserum on synapses in the superior cervical ganglion of the guinea-pig. J. Physiol. (Lond.) 277: 53-75.

Ostberg, A.-J. C., G. Raisman, P. M. Field, L. L. Iversen, and R. E. Zigmond (1976) A quantitative comparison of the formation of synapses in the rat superior cervical ganglion by its own and by foreign nerve fibres. Brain Res. 107: 445-470.

Purves, D. (1975) Functional and structural changes in mammalian sympathetic neurones following interruption of their axons. J. Physiol. (Lond.) 252: 429-463.

Purves, D. (1976) Functional and structural changes in mammalian sympathetic neurons following colchicine application to post-ganglionic nerves. J. Physiol. (Lond.) 259: 159-175.

Purves, D. (1983) Modulation of neuronal competition by postsynaptic geometry in autonomic ganglia. Trends Neurosci. 6: 10-16.

Purves, D., and R. I. Hume (1981) The relation of postsynaptic geometry to the number of presynaptic axons that innervate autonomic ganglion cells. J. Neurosci. 1: 441-452.

Purves, D., and J. W. Lichtman (1985) Geometrical differences among homologous neurons in mammals. Science 228: 298-302.

Purves, D., R. D. Hadley, and J. T. Voyvodic (1986) Dynamic changes in the dendritic geometry of individual neurons visualized over periods of up to three months in the superior cervical ganglion of living mice. J. Neurosci. 6: 1051-1060.

Rakic, P. (1972) Extrinsic cytological determinants of basket and stellate cell dendritic pattern in the cerebellar molecular layer. J. Comp. Neurol. 146: 335-354.

Rall, W. (1977) Core conductor theory and cable properties of neurons. In Handbook of Physiology, Sect. 1, The Nervous System, Vol. I Cellular Biology of Neurons, E. R. Kandel, ed., pp. 39-97, Bethesda MD.

Rubin, E. (1985) Development of the rat superior cervical ganglion: Initial stages of synapse formation. J. Neurosci. 5: 697-704.

Smolen, A. J., and P. Beaston-Wimmer (1984) Dendritic development in the rat superior cervical ganglion. Soc. Neurosci. Abstr. 10: 767.

Smolen, A. J., and G. Raisman (1980) Synapse formation in the rat superior cervical ganglion during normal development and after neonatal deafferentation. Brain Res. 181: 315-323.

Smolen, A. J., P. Beaston-Wimmer, L. L. Wright, T. Lindley, and C. Cader (1985) Neurotransmitter synthesis, storage, and turnover in neonatally deafferented sympathetic neurons. Dev. Brain Res. 23 . 211-218.

Snider, W. D. (1986) Rostrocaudal differences in dendritic growth and synaptogenesis in rat sympathetic chain ganglia. J. Comp. Neurol 244: $245-253$.

Spencer, R. F., and P. D. Coleman (1974) Influence of selective visual experience upon the morphological maturation of the visual cortex. Anat. Rec. 178: 469.

Standler, N. A., and J. J. Bernstein (1982) Degeneration and regeneration of motoneuron dendrites after ventral root crush: Computer reconstruction of dendritic fields. Exp. Neurol. 75: 600-615.

Standler, N. A., and J. J. Bernstein (1984) Dendritic alteration of spinal motoneurons after ablation of somatomotor cortex. Exp. Neurol. 83. 264-273.

Sumner, B. E. H., and W. E. Watson (1971) Retraction and expansion of the dendritic tree of motor neurones of adult rats induced in vivo. Nature 233: 273-275.

Voyvodic, J. T. (1986) A general purpose image processing language (IMAGR) facilitates visualizing neuronal structures in fixed tissue and in vivo. Soc. Neurosci. Abstr. 12: 390.

Voyvodic, J. T., and D. Purves (1984) Effect of denervation on dendritic growth in the neonatal superior cervical ganglion. Soc. Neurosci. Abstr. 10: 1082.

Wiesel, T. N., and D. H. Hubel (1963) Effects of visual deprivation on morphology and physiology of cells in the cat's lateral geniculate body. J. Neurophysiol. 26: 978-993.

Yawo, H. (1986) Geometrical changes of mouse sympathetic ganglion cells after axotomy. Soc. Neurosci. Abstr. 12: 1105. 